\title{
Reactive bay functionalized perylene monoimide-polyhedral oligomeric silsesquioxane organic electronic dye
}

\author{
Lodrick Makokha Wangatia, Bin Sun*, Ting Zeng, Meifang Zhu
}

State Key Laboratory for Modification of Chemical Fibers and Polymer Materials, College of Materials Science and Engineering, Donghua University, Shanghai 201620, P. R. China

\begin{abstract}
Aggregation-induced quenching is particularly detrimental in perylene diimides, which are characterized by a near-unity fluorescence quantum yield in solution but are far less emissive in the solid state. Previously, perylene diimide has been improved by linking it to the inorganic cage of polyhedral oligomeric silsesquioxanes. As a further study on perylene diimidepolyhedral oligomeric silsesquioxanes, we report on a double functionalized molecular structure, which can be used for substitution at the bay area and as a side group in other materials. Typical solution absorption and emission features of the perylene diimide fragment have been observed in this new reactive perylene diimide-polyhedral oligomeric silsesquioxane. Moreover, reduced stacking during aggregation and spherical particles exhibiting solid fluorescence have been obtained. Organic semiconducting material with enhanced solid state photophysical properties, like solid fluorescence is a subject of great interest owing to its possible high-tech applications in optoelectronic devices.
\end{abstract}

Keywords: perylene diimides; polyhedral oligomeric silsesquioxane; fuorescence; optoelectronics; self assembly

(C) Wroclaw University of Technology.

\section{Introduction}

In the recent past, great emphasis has been put on engineering of inexpensive organic semiconducting materials, which can be used to replace the dominant inorganic materials in optoelectronic applications. Extensive research has been carried out in the past few years and a number of organic materials with acceptable optoelectronic properties have been identified [1-4]. These organic materials have found applications in optoelectronic devices, such as thin-film transistors [5-7], photovoltaics [8-13], liquid crystals $[14,15]$, light-emitting diodes [1619], fluorescence switches [20, 21], sensors [2225], molecular wires and transistors [26, 27]. However, one major drawback of the organic semiconductors is their inferior electronic properties in solid state compared to their solution state.

Perylene diimide (PDI) is an organic semiconducting material, which has been gaining a lot of interest among researchers due to the fact that it is one of the few and best n-type organic

*E-mail: sunbin@dhu.edu.cn materials [5, 26-28]. In addition, PDI has other superior properties, which include strong absorption with high molar absorption coefficients, long fluorescence lifetime and near unity fluorescence quantum yield $[29,30]$. There has been a great desire to exploit the application of PDI in optoelectronic devices. However, other PDI, like organic semiconductors, have inferior solid state properties compared to their photophysical properties in the liquid state.

PDI has a large $\pi$-system, which makes the material susceptible to stacking. The stacking renders the development of ordered solid structures of PDI difficult and limits its solubility in organic solvents, which is an important aspect of processing electronic devices using simple methods. PDIs stacking can be reduced by constraining the $\pi-\pi$ intermolecular interactions. PDI derivatives with bulky substitutes on the $\mathrm{N}^{\prime} \mathrm{N}$ - imides provide steric hindrance to PDI core, which can greatly reduce the stacking.

Recently, a bulky polyhedral oligomeric silsesquioxanes nanoparticle (POSS) has emerged as a unique material for hybridization of polymers with many advantages [31-34]. 


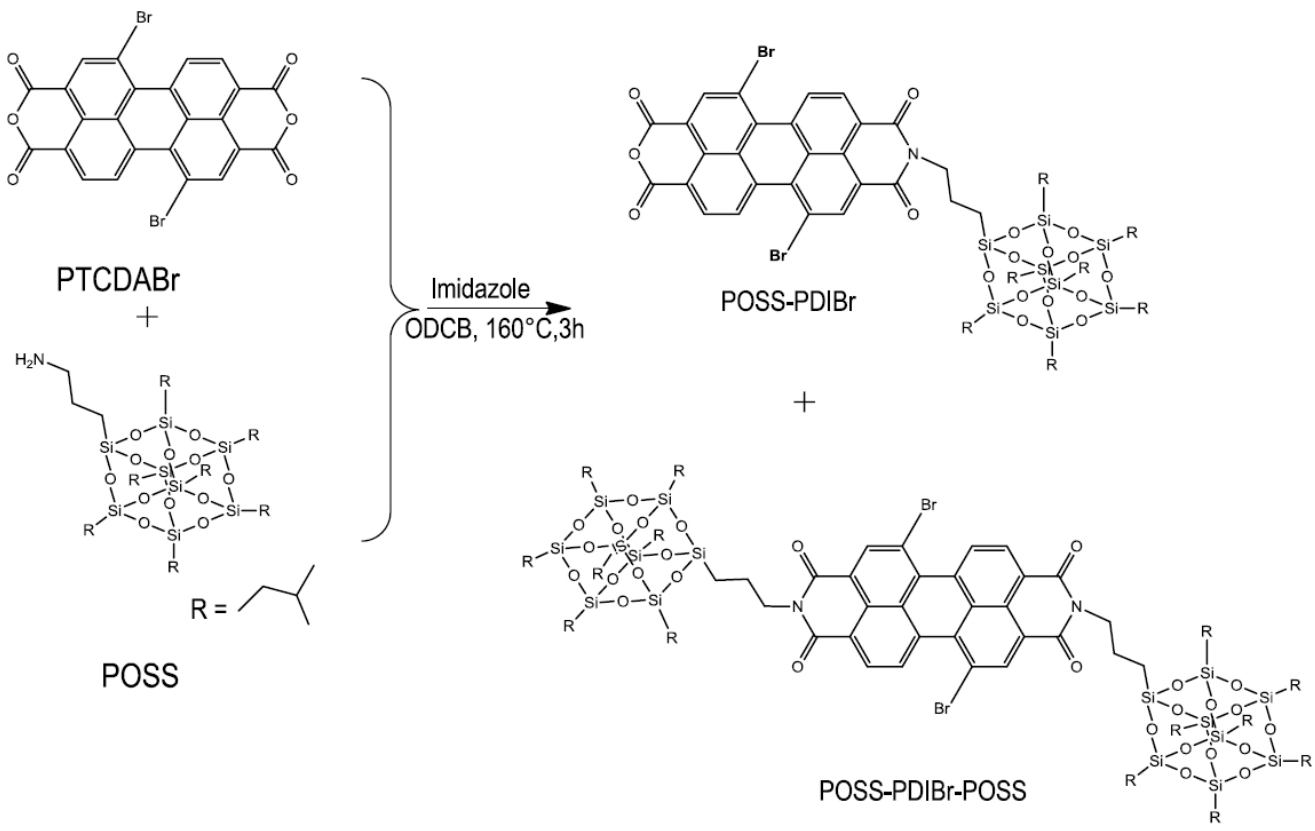

Fig. 1. Synthesis procedure for POSS-PDI ${ }_{B r}$.

Taking advantage of the bulkiness of POSS to suppress the $\pi-\pi$ interaction in PDI, we have previously end-capped planar PDI with POSS and reported on its photophysical properties [35]. Similar molecular structure has been investigated by other groups $[36,37]$. The solution UV-Vis absorption and photoluminescence properties of the POSS bound PDI (POSS-PDI-POSS) are similar to those of the parent PDI. However, aggregation studies have shown that the inherent stacking tendency in PDI is greatly suppressed thereby allowing the PDI chromophore to crystallize into highly ordered single dimensional structures of triclinic nature [36]. The crystals, unlike the parent solid PDI, have enhanced solid fluorescence and are highly soluble in organic solvents. These properties are very important in developing PDI based optoelectronic devices.

While there has been a success in incorporation of POSS on PDI, more work needs to be done to fully exploit this approach. So far there has been no work reported on creating reactive groups on the POSS-PDI-POSS for the use as a side group in other materials. In this line of thought we have designed a POSS bound PDI molecule with two reactive sites namely: (i) reactive anhydride end to allow possible attachment of POSS bound PDI to other materials and (ii) bromine reactive group at the PDI bay area to allow further substitution of PDI core for electronic properties modification.

\section{Experimental}

\subsection{Materials}

Aminopropyl isobutyl POSS (Hybrid Plastics Inc., AM0265, $\geqslant 97 \%$ ), perylene-3,4,9,10tetracarboxylic dianhydride (PTCDA, J\&K Chemical Ltd., $\geqslant 98.0 \%$ ), imidazole (J\&K Chemical Ltd., $\geqslant 99 \%$ ), 1,2-dichlorobenzene (ODCB, J\&K Chemical Ltd., anhydrous, $99 \%$ ) and other organic solvents (J\&K Chemical Ltd.) were used as received without further purification.

\subsection{Synthesis of $\mathbf{N}$-isobutyl polyhedral oligomeric silsesquioxanes-1,7-dibromo- perylene mono anhydride (POSS-PDI ${ }_{\mathrm{Br}}$ )}

PTCDA $_{\mathrm{Br}}$ was synthesized by bay area functionalizing PTCDA in a single step by reacting with bromine in concentrated sulphuric acid following previous reference [38]. POSS-PDI ${ }_{\mathrm{Br}}$ 
was synthesized as outlined in Fig. 1, using the following method: $4.54 \mathrm{~g}$ of POSS (5.1 mmol), $2.8 \mathrm{~g}$ of PTCDA $\mathrm{Br}_{\mathrm{r}},(5.1 \mathrm{mmol}), 9.2 \mathrm{~g}$ of imidazole and $10 \mathrm{~mL}$ of ODCB were placed in a round bottom flask fitted with a reflux condenser. Under argon atmosphere, the mixture was heated in an oil bath at $160{ }^{\circ} \mathrm{C}$ with vigorous stirring for $3 \mathrm{~h}$. The mixture was then cooled and extracted with $200 \mathrm{~mL}$ of chloroform several times before being washed with water. The extract was then concentrated on a rotary evaporator to give a red compound, which was a mixture of POSS-PDI $\mathrm{Br}_{\mathrm{r}}$ and POSS-PDI $\mathrm{Br}^{-}$ POSS. The two compounds were separated by column chromatography using chloroform: methanol (yield $80 \%$ ).

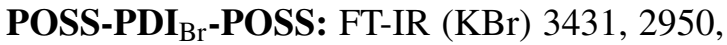
2879, 1702, 1664, 1590, 1466, 1394, 1333, 1227 , $1100,1025,835,809,757,563$ and $482 \mathrm{~cm}^{-1}$. ${ }^{1} \mathrm{H}$ NMR $\left(400 \mathrm{MHz}, \mathrm{CDCl}_{3}\right): \delta(\mathrm{ppm})=9.51(\mathrm{~d}$, 2H, ArH), 8.94 (s, 2H, ArH), 8.73 (d, 2H, ArH), 4.23 (m, 4H, $\left.\mathrm{CH}_{2}\right), 1.85$ (m, $\left.16 \mathrm{H}, \mathrm{CH}_{2} / \mathrm{i}-\mathrm{Bu} \mathrm{CH}_{2}\right)$, $0.96\left(\mathrm{t}, 84 \mathrm{H}, \mathrm{i}-\mathrm{Bu} \mathrm{CH}_{3}\right), 0.73$ to $0.6(\mathrm{~m}, 32 \mathrm{H}$, $\mathrm{Si} \mathrm{CH} 2) .{ }^{13} \mathrm{C}$ NMR $\left(400 \mathrm{MHz}, \mathrm{CDCl}_{3}\right): \delta(\mathrm{ppm})$ $=161.9,138.3,132.8,129.4,126.8,122.8,120.9$, 43.1, 25.3, 23.6, 22.2, 21.1, 9.5

POSS-PDI $_{\mathrm{Br}}$ : FT-IR (KBr) 3184, 2954, 2853, 1774, 1713, 1664, 1631, 1558, 1463, 1330, 1228, $1105,1034,954,832,742,560$ and $482 \mathrm{~cm}^{-1}$. ${ }^{1} \mathrm{H}$ NMR $\left(400 \mathrm{MHz}, \mathrm{CDCl}_{3}\right): \delta(\mathrm{ppm})=9.46(\mathrm{~d}$, 1H, ArH), 8.94 (s, 2H, ArH), 8.85 (s, 2H, ArH), $8.73(\mathrm{~d}, 1 \mathrm{H}, \mathrm{ArH}) 4.20\left(\mathrm{~m}, 2 \mathrm{H}, \mathrm{CH}_{2}\right), 1.87(\mathrm{~m}, 7 \mathrm{H}$, $\mathrm{CH}_{2} / \mathrm{i}-\mathrm{Bu} \mathrm{CH} \mathrm{CH}_{2}$ ), 0.96 (t, $42 \mathrm{H}$, i-Bu $\mathrm{CH}_{3}$ ), 0.74 to $0.60\left(\mathrm{~m}, 16 \mathrm{H}, \mathrm{Si} \mathrm{CH}_{2}\right)$.

\subsection{Equipment and sample testing}

NMR spectra were measured on a Bruker $400 \mathrm{MHz}$ NMR spectrometer with deuterated chloroform $\left(\mathrm{CDCl}_{3}, \mathrm{~J} \& \mathrm{~K}\right.$ Chemical Ltd. $\left.\geqslant 99.8\right)$ as a solvent. The ${ }^{1} \mathrm{H}$ NMR spectra were referenced to the residual proton impurities in the $\mathrm{CDCl}_{3}$ at $\delta$ $7.27 \mathrm{ppm}$, while the ${ }^{13} \mathrm{C}$ NMR spectra were referenced to $\mathrm{CDCl}_{3}$ at $\delta 77.00 \mathrm{ppm}$.

UV-Vis spectra were recorded on a Lambda 35 (Perkin Elmer) spectrophotometer. The excitation and emission spectra of the samples were investigated on a FP-6600 steady-state fluorescence spectrophotometer. All the measurements were carried out at room temperature in ambient air (unless otherwise stated) and the analysis range was 200 to $800 \mathrm{~nm}$ with a resolution of $1 \mathrm{~nm}$.

\section{Results and discussion}

\subsection{Molecular design and synthesis}

PTCDA, the parent material for making PDI has two anhydride reactive ends. Single substitution of the anhydride end results in perylene monoimide monohydride. Monoimidization of PDI improves the properties of PDI in a similar way as diimidization does, although at slightly lower level due to reduced substituent effect. However, the lower effect is compensated by the fact that the remaining anhydride group can be used as a reactive group. Functionalization of PDI at the bay area with bromine is an important process allowing incorporation of various substitutes on PDI core for electronic modification. PTCDA $\mathrm{Br}$ was condensed with amino POSS (1:1 molar ratio) in limited time $(3 \mathrm{~h})$ giving a mixture of diimide (POSS-PDI $\mathrm{Br}_{\mathrm{POSS}}$ ) and monoimide PDI (POSS-PDI ${ }_{\mathrm{Br}}$ ). The mixture was separated using simple separation techniques: extraction and column chromatography. Attempts to first condense PTCDA $\mathrm{Br}$ with amino POSS to form diimide followed by partial condensation with a base $(\mathrm{KOH})$ failed to give the monoimide. These could be due to the alkali effect on the POSS degradation [39].

The success of the synthetic procedure was confirmed by molecular characterization. The presence of both anhydride carbon $\mathrm{C}=\mathrm{O}$ and imide $\mathrm{C}=\mathrm{O}$ stretching at 1774,1713 and $1661,1631 \mathrm{~cm}^{-1}$, respectively, plus $\mathrm{C}-\mathrm{O}$ stretching peak at $1034 \mathrm{~cm}^{-1}$ on the FT-IR spectrum, were a clear indication of PDI monoimide compound. The presence of POSS cage was confirmed by the presence of $\mathrm{Si}-\mathrm{O}$ bonds at $1109 \mathrm{~cm}^{-1}, \mathrm{Si}-\mathrm{C}$ bonds at $1228 \mathrm{~cm}^{-1}$ and the $\mathrm{CH}_{2}$ bonds on POSS observed at 2954 and $2853 \mathrm{~cm}^{-1}$. Further confirmation of successful synthesis of POSS-PDI $\mathrm{Br}_{\mathrm{Br}}$ was verified by ${ }^{1} \mathrm{H}$ NMR, whereby methyl protons, methine protons and the protons of the methylene of POSS moiety were positively identified at 0.96 , 
1.87 and 0.74 to $0.60 \mathrm{ppm}$, respectively, with correct integration of the number of protons. The ${ }^{1} \mathrm{H}$ NMR for POSS-PDI $\mathrm{Br}_{\mathrm{Br}}$-POSS closely resembled that of POSS-PDI $\mathrm{Br}_{\mathrm{Br}}$ with the main difference being doubling of POSS moiety protons. ${ }^{13} \mathrm{C}$ NMR for POSS-PDI $\mathrm{Br}_{\mathrm{r}}$-POSS confirmed the presence of the POSS cage, which revealed the $\mathrm{Sp}^{3}$ carbons at 25.3, 23.6, 22.2, $21.1 \mathrm{ppm}$; these bands reflected the isobutyl chains on the POSS cage [40].

\subsection{Photophysical properties of POSS- PDI $_{\mathrm{Br}}$ in solution}

The ease in modification of PDI photophysical properties strongly depends on the nodes at the $\mathrm{N}$ imide. The use of POSS on the $\mathrm{N}$-imide has been reported to change only slightly the characteristic solution UV-Vis absorption and photoluminescence properties of PDI [34, 35]. Monoimidizing PDI with POSS and bay functionalizing it with bromine to form POSS-PDI $\mathrm{Br}_{\mathrm{Br}}$ is expected to alter the POSS-PDI $\mathrm{Br}_{\mathrm{B}}$-POSS solid state absorption and luminescent properties. The results of solution UVVis absorption and fluorescence emission tests of POSS-PDI ${ }_{\mathrm{Br}}$ and POSS-PDI $\mathrm{Br}$-POSS are shown in Fig. 2.

The UV-Vis absorption results of POSS-PDI $\mathrm{Br}_{\mathrm{Br}}$ revealed the PDI characteristic peaks similar to those of POSS-PDI $\mathrm{Br}_{\mathrm{B}}$-POSS, which were comparable to POSS-PDI-POSS [34]. POSS-PDI $\mathrm{Br}_{\mathrm{Br}}$-POSS had four absorption peaks appearing at 384, 451, 480, and $517 \mathrm{~nm}$ as shown in Fig. 2a, while POSS$\mathrm{PDI}_{\mathrm{Br}}$ gave the peaks at $422,460,493$, and $526 \mathrm{~nm}$ as illustrated in Fig. 2b. It is important to note the slight red shifting of the absorption bands of POSS$\mathrm{PDI}_{\mathrm{Br}}$ relative to POSS-PDI $\mathrm{Br}_{\mathrm{B}}$-POSS. The corresponding solution fluorescence spectrum POSS$\mathrm{PDI}_{\mathrm{Br}}$ and POSS-PDI $\mathrm{Br}$-POSS both revealed the characteristic mirror image of the absorption spectrum. However, it could be easily noticed that the fluorescence bands of POSS-PDI ${ }_{\mathrm{Br}}$-POSS were well resolved compared to those of POSS-PDI ${ }_{\mathrm{Br}}$. These slight differences in absorption and fluorescence of POSS-PDI $\mathrm{Br}_{\mathrm{Br}}$ and POSS-PDI $\mathrm{Br}_{\mathrm{Br}}$-POSS indicate that there was a small difference in aggregation brought about by reducing the steric hindrance in POSS-PDI $\mathrm{Br}_{\mathrm{Br}}$. However, the PDI absorption properties largely remained unchanged.
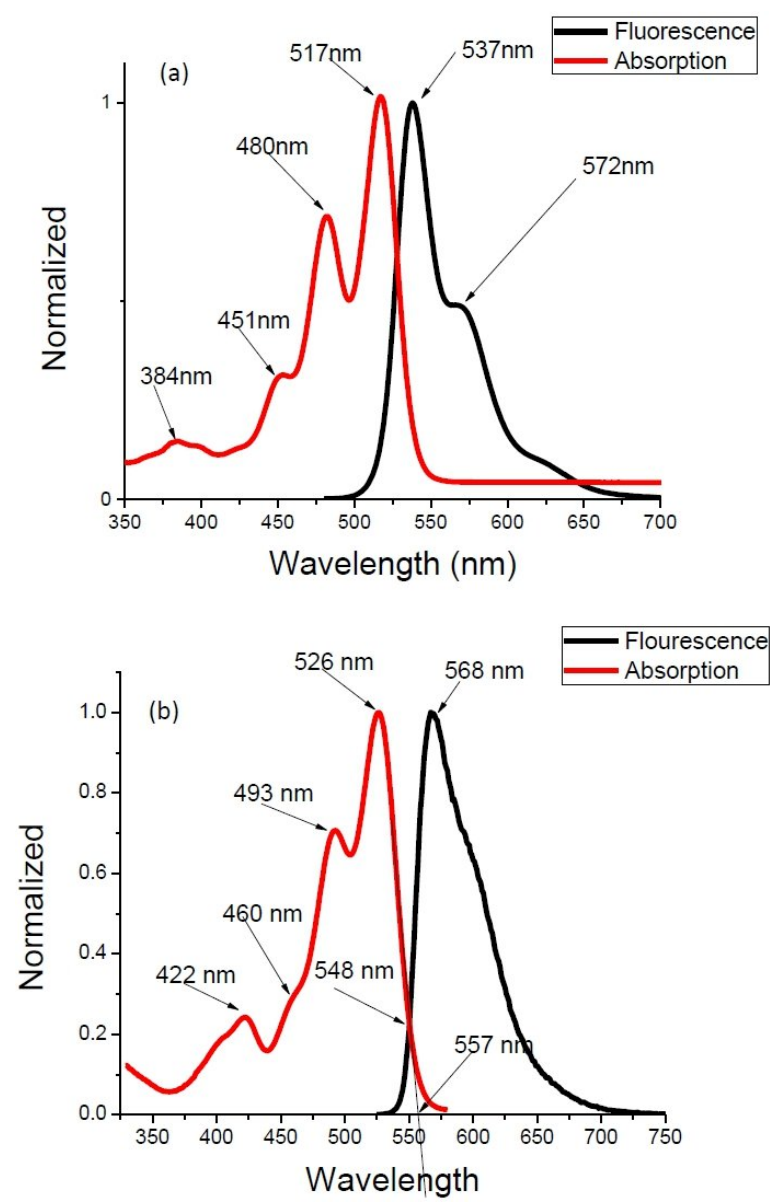

Fig. 2. UV-Vis absorption spectra (red line) and photoluminescence spectra (black line), of (a) POSS$\mathrm{PDI}_{\mathrm{Br}}$-POSS and (b) POSS-PDI $\mathrm{Br}$ in $\mathrm{CHCl}_{3}$ $\left(1.0 \times 10^{-5} \mathrm{M}\right)$ at excitation wavelength of $525 \mathrm{~nm}$.

The solubility of POSS-PDI $\mathrm{Br}_{\mathrm{Br}}$ in different organic solvents was tested using UV-Vis absorption spectra and the results have been shown in Fig. 3. The sample showed good solubility in all the tested solvents, which had varying polarity. The parent PDI usually shows limited solubility in organic solvents, which is limited only to polar solvents [41]. In our case, POSS-PDI ${ }_{B r}$ had good solubility in both polar solvents, like chloroform, and non polar solvents, like hexane. The good solubility indicates that the usually strong $\pi$-system interactions have been weakened resulting in easy solvation in the different solvents.

Solution self assembly of conjugated molecules can be used to investigate the strength of $\pi-\pi$ 


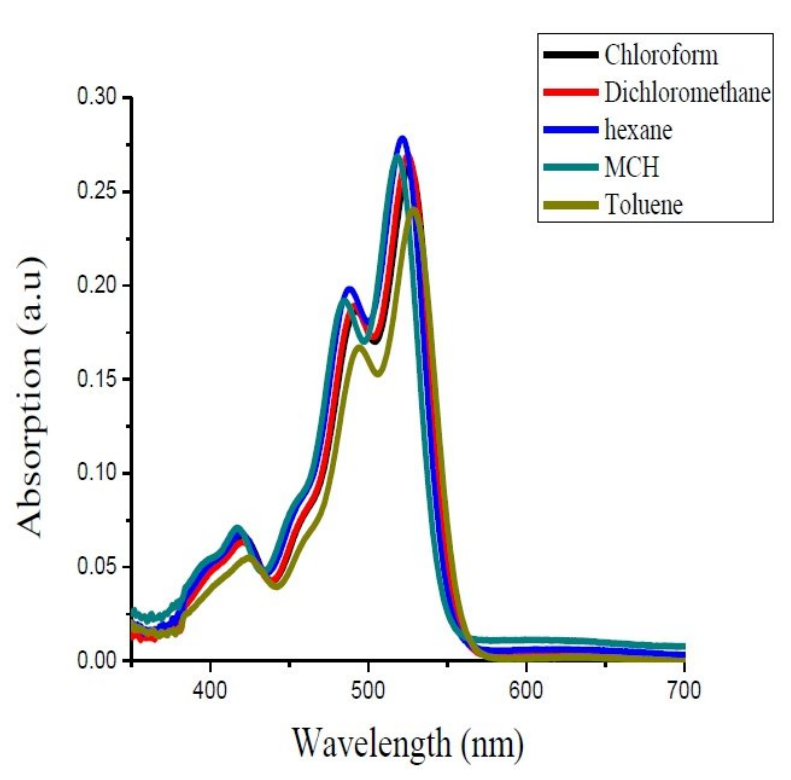

Fig. 3. UV-Vis absorption spectra of POSS-PDI $\mathrm{Br}_{\mathrm{Br}}$ in different solvents $\left(1.0 \times 10^{-5} \mathrm{M}\right)$.

interaction forces. Strong forces will tend to cause the molecules to start aggregating in very low concentrated solutions, while weak forces will only cause the molecules to start aggregating at a much higher concentration in solution. The self assembly of POSS-PDI $\mathrm{Br}_{\mathrm{r}}$ was tested by varying its concentration in toluene from $3.65 \times 10^{-7} \mathrm{M}$ to $2.92 \times 10^{-4} \mathrm{M}$ and measuring the corresponding solution absorption and fluorescence spectra. The results are depicted in Fig. 4a and Fig. 4b.

From the solution absorption spectra it can be seen that all the spectra within the tested concentration retained the same characteristic shape, only the peak intensity increased with an increase in concentration. However, no signs of peak shifting, new peak appearance at higher wavelength or maximum peak reversal, which are used to confirm the onset of aggregation, are observed within the concentration range. Their absence indicates that POSS$\mathrm{PDI}_{\mathrm{Br}}$ remained in monomeric form within the concentration range. The parent PDI shows the aforementioned aggregation signs at very low concentrations of up to $10^{-5} \mathrm{M}$ in common organic solvents [41]. Increasing POSS-PDI ${ }_{\mathrm{Br}}$ concentrations above $10^{-4} \mathrm{M}$ without an onset of aggregation is a clear indication that the molecular $\pi-\pi$ interaction
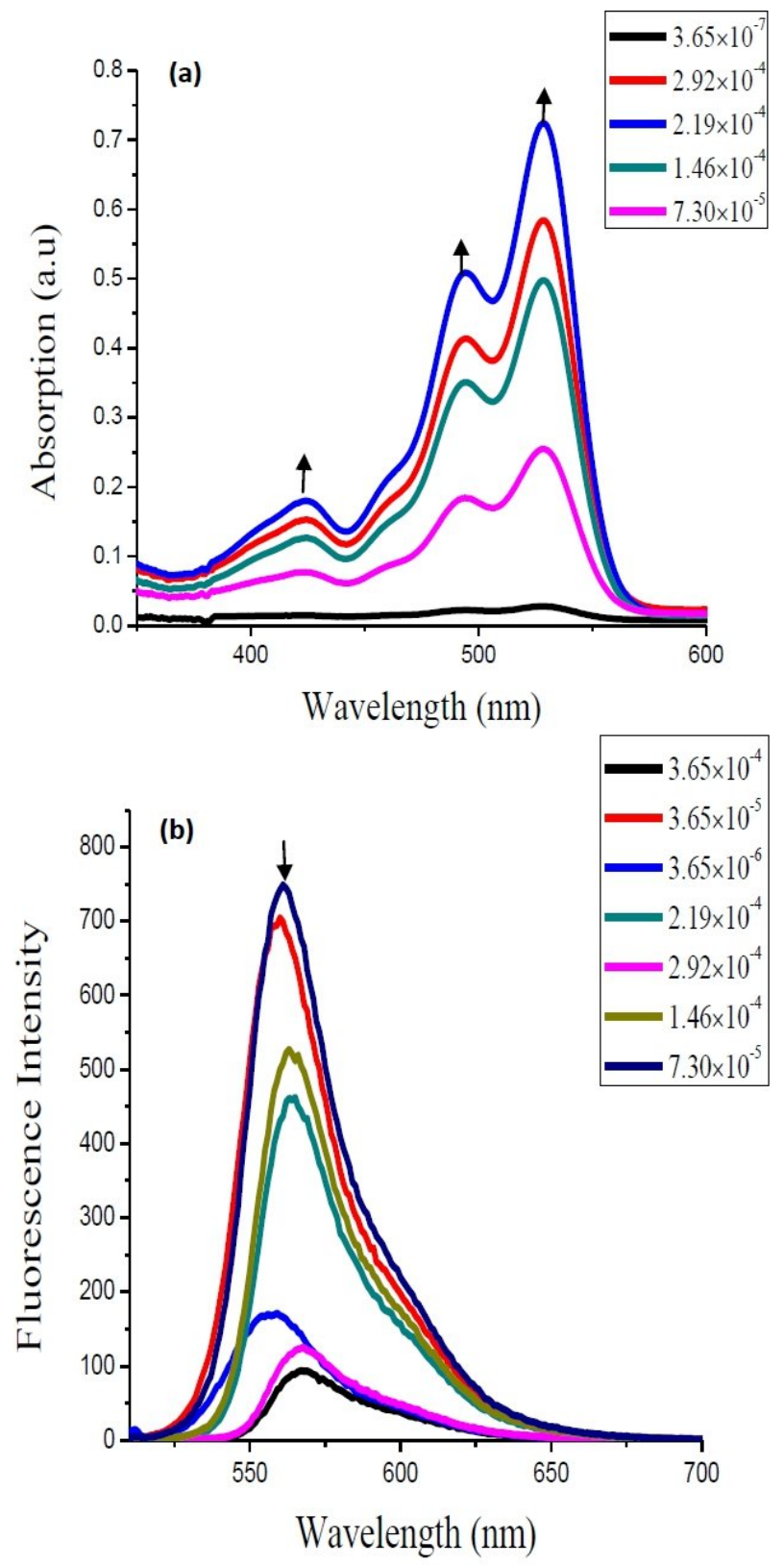

Fig. 4. Effect of concentration on the (a) UV-Vis absorption spectra of POSS-PDI $\mathrm{Br}$ and (b) florescence spectra in toluene; the arrows indicate the effect of increasing concentration.

forces are weaker than in the parent PDI. This implies that despite reducing the bulky POSS to one per molecule in the molecular design, the steric hindrance still effectively constrained the interactions. Similar observations were confirmed by the corresponding fluorescence spectra. 

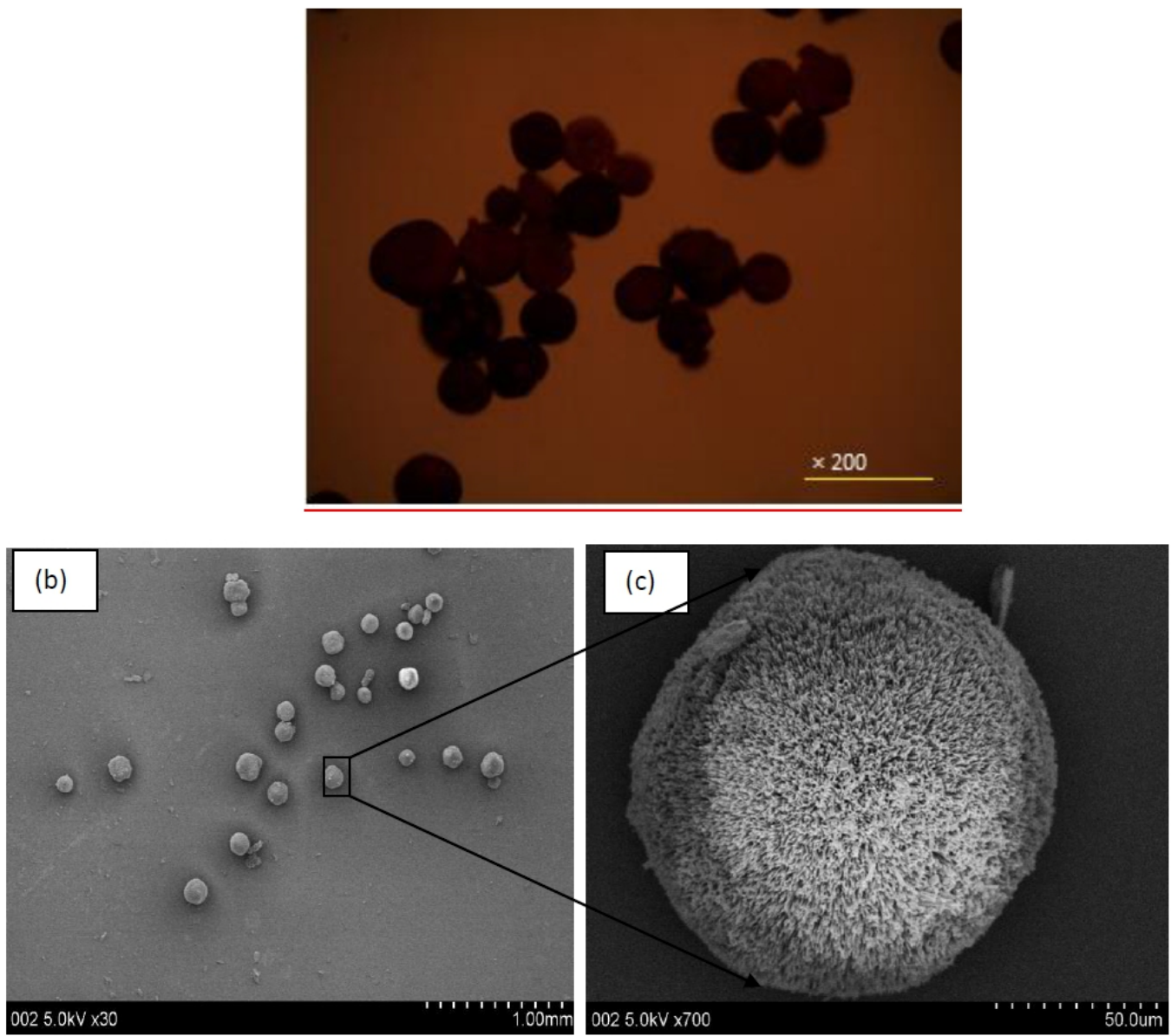

Fig. 5. Images of POSS-PDI $\mathrm{Br}_{\mathrm{Br}}$ observed with (a) optical microscope (b) and (c) with SEM.

\subsection{Crystallization of POSS-PDI ${ }_{\mathrm{Br}}$}

The $\pi-\pi$ interactions are the main forces that determine the packing of the PDI molecules. When these forces are not controlled, the molecules are randomly packed in several directions without allowing them to orient to the energy minimized positions. This condition is not conducive for developing structures, which are highly ordered. The packing can be slowed down to give molecules more time for orientation by reducing the intermolecular attraction forces. Methanol and chloroform are two immiscible solvents, which, when put together in different layers over a long period of time, slowly become miscible. The POSS-PDI ${ }_{\mathrm{Br}}$ is highly soluble in chloroform but has poor solubility in methanol. POSS-PDI $\mathrm{Br}_{\mathrm{Br}}$ crystals were prepared by dissolving the sample in a small amount of chloroform followed by adding to a large amount of methanol on the top. A buffer solution (2:1 C:M) was used to separate the two phases. After two weeks, solid particles of POSS-PDI ${ }_{B r}$ which had deposited at the base, were collected, cleaned using methanol and dried. The particles were then observed with an optical microscope. The SEM images and their morphology are shown in Fig. 5.

PDI derivates when slowly crystallized generally form single dimensional crystalline structure. We have previously crystallized POSS-PDI-POSS and formed one dimensional crystals, which were triclinic in nature [35]. Similar results have been obtained when we crystallized POSS-PDI $\mathrm{Br}_{\mathrm{Br}}$-POSS. It was surprising to note that crystallizing of POSS$\mathrm{PDI}_{\mathrm{Br}}$ resulted in very unique crystal structures of well defined spherical shape as shown in the 

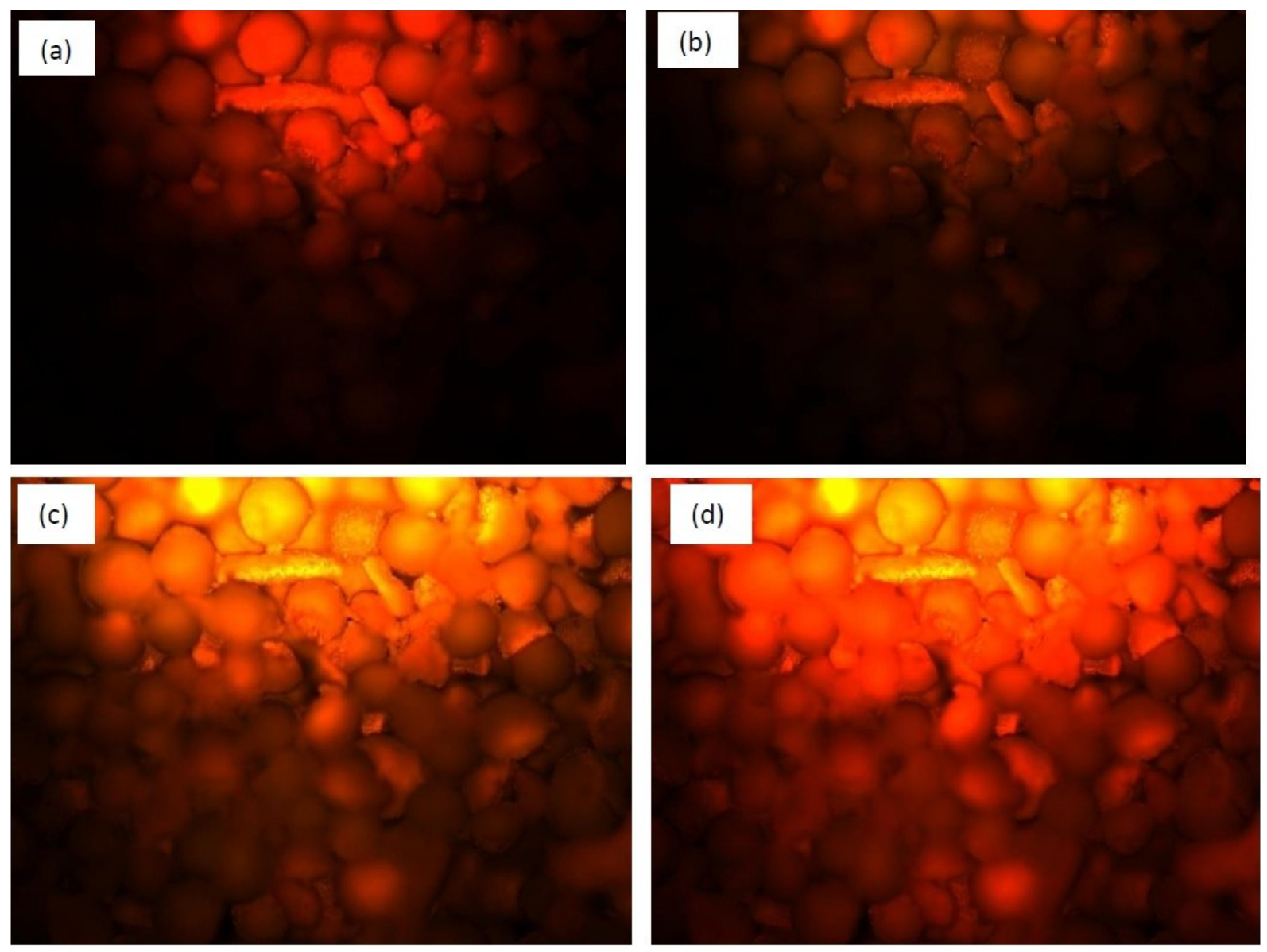

Fig. 6. Solid fluorescence images of POSS-PDI $\mathrm{Br}_{\mathrm{Br}}$ crystals observed under (a) optical microscope, (b) fluorescence microscope under green light (c) fluorescence microscope with UV light illumination, (d) fluorescence microscope under blue light.

optical microscope image in Fig. 5a. Further magnification obtained with SEM revealed that the spheres had a fibrous morphology as shown in Fig. 5c. The spherical morphology is consistent with the molecular design, which favors the close packing of molecules due to distorted $\pi-\pi$ stacking and molecular asymmetry; these conditions prevent the molecules from assembling along one direction. Spherical crystalline PDI materials have been reported to have enhanced solid state fluorescence compared to one and two dimensional crystalline PDI [42]. It is also speculated that the spheres might have some hollow space inside as evidenced by the SEM morphology, which can be used to encapsulate and release guest solutes on demand, controlled by light irradiation, which are of particular interest for cargo delivery.
In light of the foregoing results, preliminary solid fluorescence tests have been carried out on POSS-PDI $\mathrm{Br}_{\mathrm{Br}}$ using a fluorescence microscope with the results presented in Fig. 6, which confirm that the spheres emit red fluorescence light when excited using different light wavelengths. Further study should be undertaken to ascertain the enhancement of solid fluorescence by the spherical structure and the presence of hollow space in the sphere.

\section{Conclusions}

We have successfully synthesized POSS bound PDI with two reactive groups (anhydride and bromide). The photophysical properties of the molecular structure closely resembled the one of 
POSS-PDI $\mathrm{Br}_{\mathrm{Br}}$-POSS with all the main absorption peaks appearing with minimal shifting. Self assembly results showed that despite reduction of the bulky POSS from two to one per molecule, the steric hindrance was still high enough to constrain the $\pi-\pi$ interactions. Surprisingly, spherical crystal particles have been formed, which are expected to have enhanced solid fluorescence - a property highly demanded for optoelectronic device application.

\section{Acknowledgements}

We thank the National Natural Science Foundation for Distinguished Young Scholar of China (50925312), the Shanghai Nano Special Projects (1052nm02800), the Fundamental Research Funds for the Central Universities and the National Research Foundation for the Doctoral Program of Higher Education of China (20100075120012), the Program for Changjiang Scholars and Innovative Research Team in University (T2011079, IRT1221), the National Natural Science Foundation of China (50873022), the Shanghai Natural Science Foundation(13ZR1400700), the Program of Talents of Discipline to University (111-2-04), for joint financial support.

\section{References}

[1] Anthony J.E., Eaton D.L., Parkin S.R., Org. Lett., 4 (2002), 15.

[2] Horowitz G., Adv. Mater., 10 (1998), 365.

[3] Payne M.M., Delcamp J.H., Parkin S.R., ANTHONY J.E., Org. Lett., 6 (2004), 1609.

[4] Gregg B.A., Fox M.A., BARd A.J., J. Phys. Chem., 94 (1990), 1586.

[5] Horowitz G., Kouki F., Spearman P., Fichou D., Nogues C., Pan X., Garnier F., Adv. Mater, 8 (1996), 242.

[6] Chesterfield R., McKeen J.C., Newman C.R., Ewbank P.C., Da Silva Filho D.A., Bredas J.L., Miller L.L., Mann K.R., Frisbie C.D., J. Phys. Chem. B, 108 (2004), 19281.

[7] Jones B.A., Ahrens M.J., Yoon M.H., FACChetti A., Marks T.J., Wasielewski M.R., Angew. Chem. Int. Edit., 116 (2004), 6523.

[8] Schmidt-Mende L., Fechtenkotter A., Mullen K., Moons E., Friend R.H., MacKenzie J., Science, 293 (2001), 1119.

[9] Gregg B.A., J. Phys. Chem. B, 107 (2003), 4688.

[10] Gregg B.A., J. Phys. Chem., 100 (1996), 852.

[11] LiU Y., XiaO S., Li H., Li Y., LiU H., LU F., ZHUANG J., ZHU D., J. Phys. Chem. B, 108 (2004), 6256.

[12] Tamizhmani G., Dodelet J., Cote R., Gravel D., Chem. Mater., 3 (1991), 1046.

[13] Peeters E., VAn Hal P.A., Meskers S.C., JANSSEN R.A., MeIJER E., Chem.-Eur. J., 8 (2002), 4470 .
[14] Stuijk C.W., Sieval A.B., Dakhorst J.E., Van DiJK M., Kimkes P., Koehorst R.B., DOnKer H., SchaAfsma T.J., PiCKEN S.J., VAN DE CRAats A.M., J. Am. Chem. Soc., 122 (2000), 11057.

[15] Rohr U., Schlichting P., Bohm A., Gross M. Meerholz K., Brauchle C., Mullen K., Angew. Chem. Int. Edit., 37 (1998), 1434.

[16] Alibert-Fouet S., DARdel S., Bock H., Oukachmih M., ARchambeau S., Seguy I., Jolinat P., Destruel P., ChemPhysChem., 4 (2003), 983.

[17] Schouwink P., Schafer A., Seidel C., Fuchs H., Thin Solid Films, 372 (2000), 163.

[18] Ranke P., Bleyl I., Simmerer J., HaArer D., Bacher A., Schimidt H., Appl. Phys. Lett., 71 (1997), 1332.

[19] ZuKaWA T., NAKa S., OKada H., ONNAGAWA H., $J$. App. Phys., 91 (2002), 1171.

[20] Zang L., LiU R., Holman M.W., Nguyen K.T., AdAms D.M., J. Am. Chem. Soc., 124 (2002), 10640.

[21] Colacio E., Dominguez-Vera J.M., Lloret F., MoRenO-SANCHEZ J.M., KiVEKAS R., RodrigueZ A., SillanpaA R., Inorg. Chem., 42 (2003), 4209.

[22] LiU R., Holman M.W., Zang L., Adams D.M., $J$. Phys. Chem. A, 107 (2003), 6522.

[23] Holman M.W., LiU R., Zang L., YAN P., Dibenedettos A., Bower R.D., Adams D.M., $J$. Am. Chem. Soc., 126 (2004), 16126.

[24] SAuer M., Angew. Chem. Int. Edit., 42 (2003), 1790.

[25] Grimsdale A.C., Mullen K., Angew. Chem. Int. Edit., 44 (2005), 5592.

[26] Xu B., Xiao X., Yang X., Zang L., Tao N., J. Am. Chem. Soc., 127 (2005), 2386.

[27] Li X., Xu B., Xiao X., Yang X., Zang L., Tao N., Faraday Discuss., 131 (2006), 111

[28] Newman C.R., Frisbie C.D., DA Silva Filho D.A., Bredas J.-L., Ewbank P.C., Mann K.R., Chem. Mater., 16 (2004), 4436.

[29] Huang C., Barlow S., Marder S.R., J. Org. Chem., 76 (2011), 2386.

[30] Langhals H., Helv. Chim. Acta, 88 (2005), 1309.

[31] Xu H., Kuo S.-W., LeE J.-S., Chang F.-C., Macromolecules, 35 (2002), 8788.

[32] Devaux E., Rochery M., Bourbigot S., Fire Mater, 26 (2002), 149.

[33] LeU C.-M., Chang Y.-T., WeI K.-H., Macromolecules, 36 (2003), 9122.

[34] Zhang W., Muller A.H., Prog. Polym. Sci., 38 (2013), 1121.

[35] Ren X., Sun B., Tsai C.-C., Tu Y., Leng S., Li K., Kang Z., Horn R.M.V., Li X., ZhU M., J. Phys. Chem. B, 114 (2010), 4802.

[36] Zhuang X.-D., Chen Y., Zhang B., Li Y., Yu B., QIAO W., New. J. Chem., 34 (2010), 1120.

[37] Lucenti E., Botta C., Cariati E., Righetto S., Scarpellini M., Tordin E., Ugo R., Dyes Pigments, 96 (2013), 748. 
[38] Böhm A., Arms H., Henning G., Blaschka P., (BASF AG) German Pat. DE 19547209 A1, 1997, in Chem. Abstr., 127 (1997), p. 96569g.

[39] Wu S., HaYakawa T., KikUChi R., GrunZINGER S.J., KAKIMOTO M.-A., OIKAWA H., Macromolecules, 40 (2007), 5698.

[40] Sun H.-J., TU Y., WANG C.-L., VAN Horn R.M., Tsai C.-C., Graham M.J., Sun B., Lotz B., Zhang W.-B., Cheng S.Z., J. Mater. Chem., 21 (2011), 14240.
[41] Asir S., Demir A.S., ICIL H., Dyes Pigments, 84 (2010), 1.

[42] Goerl D., Zhang X., Wurthner F., Angew. Chem. Int. Edit., 51 (2012), 6328.

Received 2014-07-01

Accepted 2014-11-28 